\title{
SISTEM REKOMENDASI PRODUK UKM DI KOTA BANDUNG MENGGUNAKAN ALGORITMA COLLABORATIVE FILTERING
}

\author{
Fajar Nugroho', Mina Ismu Rahayu ${ }^{2}$ \\ ${ }^{1,2}$ STMIK BANDUNG \\ Jl. Cikutra No. 113, Cikutra Kota Bandung Jawa Barat \\ fajarnugroho.id@gmail.com ${ }^{1)}$,ismurahayu@gmail.com ${ }^{2)}$ \\ * Korespondensi: e-mail: fajarnugroho.id@gmail.com
}

\begin{abstract}
ABSTRAK
Sistem rekomendasi produk UKM (UKM Recmarketing) di kota Bandung menggunakan algoritma collaborative filtering merupakan aplikasi yang dapat mengorganisir, menginformasikan dan mempromosikan produk - produk dari UKM serta merekomendasikan item berdasarkan kemiripan antar user yang telah melakukan pembelian produk. Metodologi pembangunan perangkat lunak menggunakan metode Extreme Programming (XP) terhadap masalah yang timbul pada pengorganisasian UKM dan pemasaran produk serta rekomendasi produk. Aplikasi terbagi menjadi 2 bagian yaitu web server sebagai pusat data dan aplikasi android untuk pengguna client mobile. Aplikasi ini menggunakan sebuah framework Code Igniter (CI) dari sisi web servernya dan web services API (Application Programming Interface) yang digunakan yaitu Restful serta dari sisi androidnya menggunakan bahasa pemrograman Java, adapun dari pertukaran data antara client dengan server menggunakan JSON untuk mendukung kinerja sistem sehingga resiko operasional dapat berkurang. Adapun aplikasi nantinya akan memudahkan para UKM untuk memasarkan produk - produknya dengan lebih mudah, dengan data produk yang lebih teroganisir dan memudahkan kepada para customers untuk mencari produk dan menemukan produk yang dibutuhkannya serta customers mendapatkan penawaran - pewaran diskon.
\end{abstract}

Kata Kunci: Collaborative Filtering, UKM, Mobile Android.

\begin{abstract}
UKM Product recommendation system (UKM Recmarketing at Bandung City using algorithm collaborative filtering is an application that can organize, inform and also promote the products from UKM. This application also recommend item based on the product which user already purchased before. This software development methodology using Extreme Programming (XP) against the problem when organizing the UKM and also when do product marketing as well as product recommendations. This application divided into two parts, first one is the web server which serve as a data center and the other one is android applications for mobile client users. This application built using a framework named Code Igniter (CI) for the web server side, Restful for the API (Application Programming Interface), and Java programming language for the Android application development. The method of data communication between the client and the server this application using JSON to support the performance of the system, this mean that the risk of each operations can be reduced. The Application designed to help the UKM market their products more easily, with more organized data of the product, also make it easier for the customers to search for products and find the products they need as well as the customers get a discount offer.
\end{abstract}

Keywords: Collaborative Filtering, UKM, Android Mobile. 


\section{Pendahuluan}

Di era dimana sosial media menjadi bagian dari keseharian mulai dari anak kecil sampai orang dewasa, begitu pun banyak yang menggunakan sosial media untuk berjualan, selain menggunakan social media, adapun yang menggunakan beberapa aplikasi lain seperti shopee, tokopedia, bukalapak dan lain - lain. Pada setiap aplikasi jual-beli baik menggunakan sosial media ataupun aplikasi yang lain, disana diterapkan sistem rekomendasi. Akan tetapi sistem rekomendasi tidah hanyak digunakan untuk penjualan dan pembelian barang akan tetapi masih ada beberapa hal lain seperti rekomendasi untuk pertemanan, rekomendasi untuk penyewaan hotel, rekomendasi tempat - tempat wisata dan lain - lain. Sistem rekomendasi merupakan sistem yang bertujuan untuk memperkirakan informasi yang menarik bagi pengguna dan juga membantu user dalam menentukan pilihannya. Pada penelitian kali ini sistem rekomendasi yang digunakan adalah menggunakan kasus untuk penjualan makanan khusus para umkm di kota Bandung.

\section{A. Recommender System (Sistem Rekomendasi)}

Seperti yang dijelaskan di atas sistem rekomendasi merupakan sistem yang bertujuan untuk memperkirakan informasi yang menarik bagi pengguna dan juga membantu user dalam menentukan pilihannya. Puspaningtyas Sanjoyo (2010) dalam jurnalnya yang berjudul "Sistem Rekomendasi Nilai Mata Kuliah Menggunakan Metode Content-Based Filtering" menjelaskan bahwa Sistem rekomendasi merupakan sistem yang bertujuan memperkirakan informasi yang menarik bagi penggunanya dan juga membantu calon konsumen dalam memutuskan barang apa saja yang akan dibelinya[1].

Collaborative filtering adalah melakukan penyaringan data berdasarkan kemiripan karakteristik konsumen sehingga mampu memberikan informasi yang baru kepada konsumen karena sistem memberikan informasi berdasarkan pola satu kelompok konsumen yang hampir sama. Perbedaan minat pada beberapa anggota kelompok menjadikan sumber informasi baru yang mungkin bermanfaat bagi anggota kelompok lainnya. Collaborative Filtering ini dibagi menjadi dua kelas yaitu user-based dan item-based (Schafer dkk, 2007).

\section{1) User-Based Collaborative Filtering}

User-based nearest neighbour algorithm menggunakan teknik statistika untuk menemukan sekumpulan pengguna, dikenal sebagai tetangga (neighbour), yang memiliki sejarah setuju dengan pengguna yang menjadi sasaran. Setelah sekumpulan tetangga terbentuk, sistem menggunakan algoritma yang berbeda untuk menggabungkan kesukaan neighbours untuk menghasilkan prediksi atau rekomendasi N-teratas untuk active user. (Sarwar dkk, 2001).

\section{2) Item-to-Item Collaborative Filtering}

Item-based collaborative filtering merupakan metode rekomendasi yang didasari atas adanya kesamaan antara pemberian rating terhadap suatu produk dengan produk yang dibeli. Dari tingkat kesamaan produk, kemudian dibagi

dengan parameter kebutuhan pelanggan untuk memperoleh nilai kegunaan produk. Produk yang memiliki nilai kegunaan tertinggilah yang kemudian dijadikan rekomendasi (Purwanto, 2009).

Berikut ini beberapa ulasan sistem rekomendasi yang dirangkum kedalam sebuah jurnal :

a. Item Collaborative Filtering untuk Rekomendasi Pembelian Buku secara Online

Pada jurnal yang dibuat oleh Shofwatul Uyun, Imam Fahrurrozi dan Agus Mulyanto yang berjudul "Item Collaborative Filtering untuk Rekomendasi Pembelian Buku Secara Online” menyebutkan bahwa Collaborative filtering yang dibuat untuk rekomendasi buku adalah pada penyaringan data berdasarkan kemiripan karakteristik konsumen sehingga mampu memberikan informasi yang baru kepada konsumen karena sistem memberikan informasi berdasarkan pola satu kelompok konsumen yang hampir sama. Cara perhitungannya yaitu menggunakan rating dari masing - masing pengguna, setiap pengguna memberikan rating 1- 5 terhadap buku yang dipilihnya, kemudian cara kedua yaitu baik atau buruknya buku tersebut. Perbedaan minat pada beberapa anggota kelompok menjadikan sumber informasi baru yang mungkin bermanfaat bagi anggota kelompok lainnya[2].

b. Perancangan Sistem Rekomendasi Sistem Pakaian Distro dengan Menggunakan Item Collaborative Filtering 
Pada Jurnal "Perancangan Sistem Rekomendasi Pakaian Distro dengan Menggunakan Item Collaborative Filtering" yang dibuat oleh Hardi Susanto menyebutkan bahwa Rekomendasi item dalam hal ini (Pakain) didasari atas adanya kesamaan antara pemberian rating terhadap suatu produk (pakaian) dengan produk yang dibeli. Dari tingkat kesamaan produk, kemudian dibagi dengan parameter kebutuhan pelanggan untuk memperoleh nilai kegunaan produk. Produk yang memiliki nilai kegunaan tertinggilah yang kemudian dijadikan rekomendasi (Purwanto, 2009)[3].

c. Content Based Recommender System Algoritma Apriori

Content Based Recommender System Menggunakan Algoritma Apriori Pada Jurnal yang dibuat oleh Rahma Oktoria, Warih Maharani, dan Yanuar Firdaus dengan Judul "Content Based Recommender System Menggunakan Algoritma Apriori” menjelaskan bahwa Content Based Recommender yaitu merekomendasikan item baru kepada user target berdasarkan kemiripan feature yang dikandung oleh item sebelumnya yang disukai user tersebut dengan melihat positif rating item[1].

Maka kesimpulan dari beberapa jurnal menyebutkan bahwa Collaborative Filtering bergantung pada rating yang diberikan oleh masing - masing user ke setiap item sedangkan content based recommender lebih menekankan kepada kemiripan dari masing - masing feature setiap item tersebut.

\section{METODOLOGI PENELITIAN}

Algoritma yang digunakan dalam pembuatan sistem ini yaitu collaborative filtering. Prinsip kerja dari algoritma collaborative filtering adalah memberikan rekomendasi atau prediksi item berdasarkan pada opini pengguna-pengguna yang mempunyai kemiripan. Opini yang diberikan bisa bersifat eksplisit maupun implisit. Tujuan dari algoritma collaborative filtering adalah menganjurkan item baru atau memprediksikan evaluasi item kepada pengguna khusus berdasarkan pada ketertarikan sebelumnya dari pengguna dan opini dari pengguna-pengguna lain yang mempunyai ketertarikan yang mirip. Opini bisa diberikan secara eksplisit oleh pengguna berupa nilai rating atau bisa juga secara implisit dihasilkan dari riwayat pembelian, dengan melakukan analisis terhadap logs, navigation history atau dengan cara yang lain.

Adapun flowchart untuk studi kasus algoritma collaborative filtering yang digunakan pada kasus kali yaitu : 


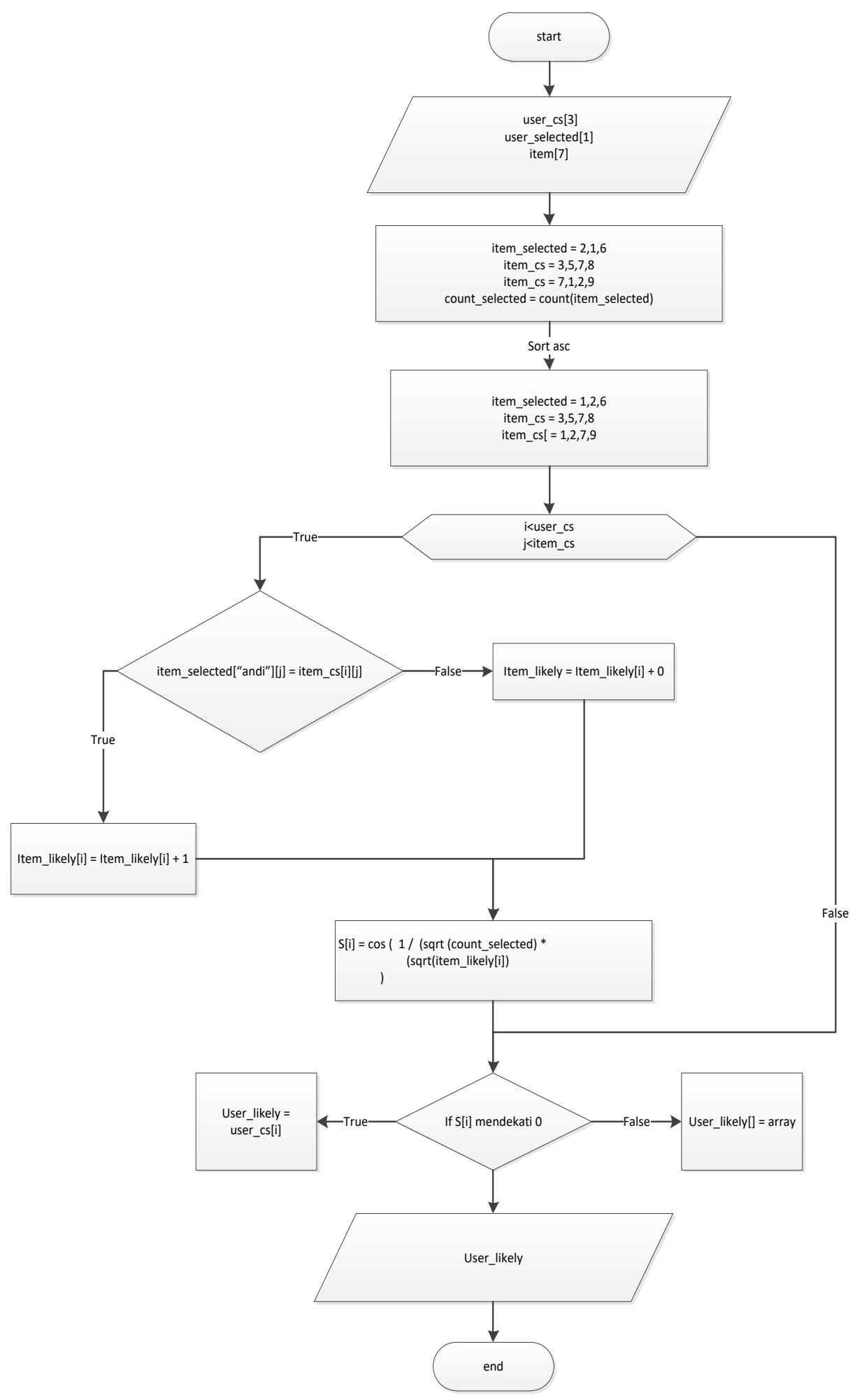

Gambar 2.1 Flowchart Studi Kasus Collaborative Filtering UKM Recmarketing

\section{HASIL DAN DISKUSI}

A. Analisa Kebutuhan Sistem

Analisa kebutuhan sistem adalah analisa yang berisi pengamatan dari masalah yang ada. Dalam reomendasi item dibutuhkan variabel - variabel untuk pengelompokan minat atau kesukaan sehingga item yang direkomendasikan bisa lebih spesifik dan detail. Variabel - variabel umum yang digunakan yaitu : 
1) Usia

Usia digunakan untuk filter data, dikarenakan kelompok usia tertentu biasanya lebih menyukai item item tertentu juga. Contohnya usia remaja lebih menyukai makanan - makan yang pedas dibandingkan usia setengah baya ataupun anak - anak.

Usia dikelompokan pada beberapa golongan yaitu :

\begin{tabular}{|l|l|l|}
\hline \multicolumn{2}{|c|}{ Tabel 3.1 Kelompok Usia } \\
\hline Kode & Kelompok Usia (Tahun) & Nama \\
\hline 1. & $2-11$ & Anak - anak \\
\hline 2. & $12-25$ & Remaja \\
\hline 3. & $26-45$ & Dewasa \\
\hline 4. & $46+$ & Lansia \\
\hline
\end{tabular}

2) Wilayah

Wilayah digunakan sebagai filter untuk rekomendasi dikarenakan wilayah mempunyai peranan dalam hal kesukaan terhadap makanan tertentu, seperti Yogyakarta lebih menyukai makanan manis (tempe bacem, tahu coklat manis) sedangkan padang lebih menyukai makanan pedas - pedas.

Analisis wilayah mempunyai arti yaitu kota tempat user tinggal.

\begin{tabular}{|l|l|}
\multicolumn{2}{|c|}{ Tabel 3.2 Kota } \\
\hline Kode & Nama Kota \\
\hline 1. & Bandung \\
\hline 2. & Jakarta \\
\hline 3. & Yogyakarta \\
\hline 4. & Surabaya \\
\hline 5. & Padang \\
\hline
\end{tabular}

B. Analisa Kategori / Pengelompokan

Dari hasil analisa, penulis dapat menganalisa beberapa hal yang dibutuhkan,yaitu :

1) Analisis Kategori/ Pengelompokan Makanan di UKM

Adapun pengelompakan untuk barang - barang yang akan di jual adalah sebagai berikut :

a. Makanan

Makanan dikelompokan dengan beberapa variabel:

Kategori Makanan :

\begin{tabular}{|l|l|l|}
\multicolumn{3}{|c|}{ Tabel 3.3Kategori Makanan } \\
\hline No. & Kode & Nama \\
\hline 1. & 1. & Makanan ringan (cemilan) \\
\hline 2. & 2. & Makanan Tradisional \\
\hline 3. & 3. & Makanan Western \\
\hline 4. & 4. & Makanan Pembuka (Appetizer) \\
\hline 5. & 5. & Makanan Penutup (Desert) \\
\hline 6. & 6. & Makanan Cepat Saji (Junk Food) \\
\hline
\end{tabular}

b. Minuman

Minuman dikelompokan dengan beberapa variabel :

Kategori Minuman :

\begin{tabular}{|l|l|l|}
\multicolumn{3}{|c|}{ Tabel 3.4 Kategori Minuman } \\
\hline No. & Kode & Nama \\
\hline 1. & 1. & Kopi \\
\hline 2. & 2. & The \\
\hline 3. & 3. & Susu \\
\hline 4. & 4. & Jus \\
\hline
\end{tabular}

Dari pengelompokan yang telah dibuat, jika item yang dicari atau dibutuhkan oleh user ada salah satu jenis yang sama, maka akan direkomendasikan, meskipun berbeda kelompok.

C. Analisis cara penilaian rekomendasi oleh sistem

Cara Penilaian rekomendasi yang dilakukan oleh sistem dilakukan dengan menghitung beberapa kriteria yaitu : 
1) Rating dari user

Cara penilaian rating dari user yaitu dengan memberikan rating ke masing - masing item oleh user, nilai tersebut dimulai dari 1 hingga 5 .

2) Harga

Adapun harga untuk rekomendasi yaitu menitikberatkan pada harga yang termurah, dikarenakan semua user / pembeli pasti menginginkan harga yang paling murah. Ketika harga paling murah, maka oleh sistem item tersebut akan menempati posisi paling atas dibandingkan item-item yang lainnya.

3) Jarak user ke lokasi penjualan UKM

Analisis jarak diambil dari jarak yang paling dekat dengan lokasi user ketika melakukan pencarian item atau barang yang dibutuhkannya. Ketika ada jarak yang paling dekat maka item tersebut akan menempati posisi paling atas dibandingkan item yang lainnya, akan tetapi jarak adalah varibel kedua setelah harga pada indexing item.

4) History / Logs produk

History (riwayat pencarian) adalah mempelajari jejak atau kebiasaan (habit) dari pengguna tersebut. Dengan melakukan analisis terhadap logs, navigation history atau dengan cara yang lain (Sarwar,2001). Misalkan user tersebut sering mencari baju dengan warna merah, maka akan di rekomendasikan aksesoris yang berwarna merah, dikarenakan melakukan analisis dari kelompok warna yang sama.

History (riwayat pencarian) adalah mempelajari jejak atau kebiasaan (habit) dari pengguna tersebut.Dengan melakukan analisis terhadap $\log s$, navigation history atau dengan cara yang lain (Sarwar,2001).

Misalkan user tersebut sering mencari baju dengan warna merah, maka akan di rekomendasikan aksesoris yang berwarna merah,dikarenakan melakukan analisis dari kelompok warna yang sama.

5) Usia

Analisis usia mempengaruhi kepada kesukaan / kegemaran dari setiap user, misalkan kelompok usia remaja, lebih gemar menggunakan pakaian yang styles sedangkan kelompok usia tua, lebih gemar menggunakan pakaian yang santai dan cukup terlihat rapi.

6) Wilayah

Wilayah mempengaruhi kesukaan / kegemaran pada makanan ataupun pakaian, seperti wilayah yang berdomisili di kota Padang lebih menyukai pedas, sedangkan kota seperti Yogyakarta lebih menyukai makanan yang manis.

\section{Analisis Collaborative Filtering}

Recommender System merupakan model penyelesaian masalah yang menerapkan teknik - teknik tertentu pada pembuatan rekomendasi untuk pemilihan suatu informasi, produk dan jasa (Goldberg, 2001). Terdapat dua pendekatan dalam mengembangkan suatu recommender system yaitu content-based dan collaborative filtering (Kangas,2002).

Pendekatan content-based akan menyediakan rekomendasi dengan cara membandingkan representasi konten yang terkandung dalam suatu item dengan representasi konten yang diinginkan pengguna. Untuk itu, harus dilakukan proses indexing, yaitu melakukan ekstraksi informasi yang dikandung item.

Sedangkan sistem yang dibangun dengan pendekatan collaborative filtering akan bekerja dengan cara mempelajari kebiasaan para pencari informasi dan membangun profil pencari informasi, kemudian memberikan rekomendasi. Ide awal yang melandasi munculnya teknik collaborative filtering adalah perbandingan rasa suka atau tidak suka seseorang, misalnya A, terhadap sekumpulan produk, dengan orang lain, misalnya B, untuk memprediksi pilihan A untuk produk yang lain (Goldberg, 2001 dan Kangas, 2002).

\section{E. Studi Kasus}

Studi kasus rumus untuk rekomendasi collaborative filtering yaitu menggunakan persamaan cosine based similarity dengan perhitungan vektor. Dua vektor dikatakan sama jika membentuk sudut $0^{0}$ atau nilai cosinusnya 1, dengan kata lain user dikatakan mirip jika nilai cosinusnya mendekati 1.

Contoh studi kasus : 
Adapun referensi data produk digambarkan sebagai berikut :

Tabel 3.6 Referensi data produk

\begin{tabular}{|l|l|l|}
\hline No & Kode Item & Nama Produk \\
\hline 1. & 1 & Tahu Gejrot \\
\hline 2. & 2 & Sate Padang \\
\hline 3. & 3 & Almond Chicken \\
\hline 4. & 4 & Beef Steak \\
\hline 5. & 5 & Mie Aceh \\
\hline 6. & 6 & Rawon \\
\hline 7. & 7 & Surabi \\
\hline 8. & 8 & Hamburger Mini \\
\hline 9. & 9 & Martabak Bangka \\
\hline
\end{tabular}

Ada 3 user dalam studi kasus, yaitu Andi, Ahmad dan Bella, masing - masing user mempunya variabel usia dan wilayah. Sebelum dihitung menggunakan rumus collaborative filtering maka masing - masing user - user tersebut difilter berdasarkan kelompok usia dan wilayah, akan tetapi dalam studi kasus ini, langsung pada perhitungan collaborative filtering.

1) User Andi

a. Usia : 21 tahun

b. Wilayah : Kota Bandung

c. Daftar history pembelian :

\begin{tabular}{|l|l|l|l|}
\hline Pembelian Ke & Kode item & Nama & Kabel 3.7 Daftar makanoleh Andi \\
\hline 1. & 2 & Sate Padang & Makanan Tradisional \\
\hline 2. & 1 & Tahu Gejrot & Makanan Tradisional \\
\hline 3. & 6 & Rawon & Makanan Tradisional \\
\hline
\end{tabular}

Untuk mempermudah melakukan perhitungan rekomendasi maka akan diurutkeun berdasarkan kode item dari pembelian, sehingga tabelnya akan berubah seperti dibawah ini :

Tabel 3.8 Daftar makanan Andi yang telah diurutkan

\begin{tabular}{|l|l|l|l|}
\hline Pembelian Ke & Kode item & Nama & Kategori \\
\hline 2. & 1 & Tahu Gejrot & Makanan Tradisional \\
\hline 1. & 2 & Sate Padang & Makanan Tradisional \\
\hline 3. & 6 & Rawon & Makanan Tradisional \\
\hline
\end{tabular}

2) User Ahmad

a. Usia : 23 tahun

b. Wilayah : Kota Bandung

c. Daftar history pembelian

\begin{tabular}{|l|l|l|l|}
\hline Pembelian Ke & $\begin{array}{l}\text { Kode } \\
\text { item }\end{array}$ & Namel 3.9 Daftar makanan yang dibeli oleh Ahmad \\
\hline 1. & 7 & Surabi & Kategori \\
\hline 2. & 1 & Tahu Gejrot & Makanan Tradisional \\
\hline 3. & 2 & Rawon & Makanan Tradisional \\
\hline 4. & 9 & Martabak Bangka & Makanan Tradisional \\
\hline
\end{tabular}

Untuk mempermudah melakukan perhitungan rekomendasi maka akan diurutkeun berdasarkan kode item dari pembelian, sehingga tabelnya akan berubah seperti dibawah ini :

Tabel 3.10 Daftar makanan Ahmad yang telah diurutkan

\begin{tabular}{|l|l|l|l|}
\hline $\begin{array}{l}\text { Pembelian } \\
\text { Ke }\end{array}$ & Kodeitem & Nama & Kategori \\
\hline 2. & 1 & Tahu Gejrot & Makanan Tradisional \\
\hline 3. & 2 & Rawon & Makanan Tradisional \\
\hline 1. & 7 & Surabi & Makanan Tradisional \\
\hline 4. & 9 & Martabak Bangka & Makanan Tradisional \\
\hline
\end{tabular}

3) User Bella
a. Usia : 28 tahun
b. Wilayah : Kota Cimahi
c. Daftar history pembelian 


\begin{tabular}{|l|l|l|l|}
\multicolumn{3}{|c|}{ Tabel 3.11 Daftar makanan yang dibeli oleh Bella } \\
\hline Pembelian Ke & $\begin{array}{l}\text { Kode } \\
\text { item }\end{array}$ & Nama & Kategori \\
\hline 1. & 3 & Almond Chicken & Makanan Western \\
\hline 2. & 5 & Mie Aceh & Makanan Tradisional \\
\hline 3. & 7 & Surabi & Makanan Tradisional \\
\hline 4. & 8 & Hamburger Mini & Makanan Junk Food \\
\hline
\end{tabular}

Dikarenakan kode item telah terurut dari yang kecil sampai yang besar, maka tidak ada perubahan tabel. Untuk merekomendasikan item ke 4 kepada Andi, dengan cara menghitung dari history pembelian dan membandingkan Ahmad dan Bella, maka berikut adalah tabel untuk masing - masing user dari item yang telah dibeli :

\begin{tabular}{|l|l|l|l|l|}
\hline \multirow{2}{*}{$\#$} & Makanan yang telah dibeli 3.12 History pembelian \\
\cline { 2 - 5 } & Pembelian1 & Pembelian2 & Pembelian3 & Pembelian4 \\
\hline Andi & 1 & 2 & 6 & x \\
\hline Ahmad & 1 & 2 & 7 & 9 \\
\hline Bella & 3 & 5 & 7 & 8 \\
\hline
\end{tabular}

Adapun rumus yang digunakan yaitu collaborative filtering:

$$
s(\boldsymbol{i}, \boldsymbol{j})=\cos (\overrightarrow{\boldsymbol{R}}(*, \boldsymbol{i}), \overrightarrow{\boldsymbol{R}}(*, \boldsymbol{j}))=\frac{\overrightarrow{\boldsymbol{R}}(*, i) \cdot \overrightarrow{\boldsymbol{R}}(*, \boldsymbol{j})}{\|\overrightarrow{\boldsymbol{R}}(*, i)\| *\|\overrightarrow{\boldsymbol{R}}(*, \boldsymbol{j})\|}
$$

Cara perhitungannya adalah untuk user Andi (sebagai user yang akan diberi rekomendasi item), maka semua nilainya adalah 1 karena sebagai acuan pembandingnya, lalu melihat pembelian ke 1 dengan user Andi akan dibandingkan dengan pembelian ke 1 juga dengan user Ahmad, jika item yang dibeli sama maka akan diberi nilai 1 sedangkan jika beda maka bernilai 0 , kemudian dibandingkan dengan pembelian ke 2, apakah item yang dibeli oleh Andi dan Ahmad sama atau tidak, dan seterusnya seperti itu.

Maka tabel yang akan terbentuk adalah sebagai berikut :

Tabel 3.13 Hasil penilaian

\begin{tabular}{|l|l|l|l|l|}
\hline \multirow{2}{*}{$\#$} & \multicolumn{4}{|l|}{ Nilai } \\
\cline { 2 - 5 } & Pembelian1 & Pembelian2 & Pembelian3 & Pembelian4 \\
\hline Andi & 1 & 1 & 1 & \\
\hline Ahmad & 1 & 1 & 0 & \\
\hline
\end{tabular}

Perhitungan antara Andi dan Ahmad.

$\mathrm{S}_{0}\left(\mathrm{U}_{1}, \mathrm{U}_{2}=\cos \frac{(\mathbf{1} * \mathbf{1}+\mathbf{1} * \mathbf{1}+\mathbf{1} * \mathbf{0})}{\sqrt{\mathbf{1}^{2}+\mathbf{1}^{2}+\mathbf{1}^{2}} * \sqrt{\mathbf{1}^{2}+\mathbf{1}^{2}+\mathbf{0}^{2}}}\right.$

$\mathrm{S}_{0}\left(\mathrm{U}_{1}, \mathrm{U}_{2}\right)=\cos \frac{\mathbf{2}}{\sqrt{\mathbf{3} * \sqrt{\mathbf{2}}}}$

$\mathrm{S}_{0}\left(\mathrm{U}_{1}, \mathrm{U}_{2)}=\cos \frac{2}{\sqrt{6}}=\frac{2}{2.449}=0.816\right.$

$\mathrm{S}_{0}\left(\mathrm{U}_{1}, \mathrm{U}_{2}\right)=\cos 0.816=0.6154$

Tabel 3.14 Hasil penilaian

\begin{tabular}{|l|l|l|l|l|}
\hline \multirow{2}{*}{$\#$} & Nilai & Pembelian2 & Pembelian3 & Pembelian4 \\
\cline { 2 - 5 } & Pembelian1 & 1 & 1 & \\
\hline Andi & 1 & 0 & 1 & \\
\hline Bella & 0 & 0 & 1 \\
\hline
\end{tabular}

Untuk Persamaan berikutnya yaitu Andi dan Bella

$\mathrm{S}_{0}\left(\mathrm{U}_{1}, \mathrm{U}_{2)}=\cos \frac{(\mathbf{1} * \mathbf{0}+\mathbf{1} * \mathbf{0}+\mathbf{1} * \mathbf{1})}{\sqrt{\mathbf{1}^{2}+1^{2}+1^{2}} * \sqrt{\mathbf{0}^{2}+\mathbf{0}^{2}+\mathbf{1}^{2}}}\right.$

$\mathrm{S}_{0}\left(\mathrm{U}_{1}, \mathrm{U}_{2)}=\cos \frac{\mathbf{1}}{\sqrt{\mathbf{3}} * \sqrt{\mathbf{1}}}\right.$

$\mathrm{S}_{0}\left(\mathrm{U}_{1}, \mathrm{U}_{2)}=\cos \frac{1}{\sqrt{3}}=\frac{1}{1.732}=0.557\right.$

$\mathrm{S}_{0}\left(\mathrm{U}_{1}, \mathrm{U}_{2}\right)=\cos 0.816=0.9553$ 


\section{KESIMPULAN}

Disimpulkan bahwa rekomendasi yang lebih mendekati kecocokan untuk Andi adalah Ahmad dikarenakan item - item yang dibeli oleh Ahmad lebih mirip dibandingkan item - item yang dibeli oleh Bella, maka item yang akan direkomendasikan adalah item yang memilki kode 9 dengan nama Martabak Bangka. Dari perhitungannya pun lebih besar Andi dan Ahmad yaitu 0.816 dibandingkan dengan Andi dan Bella yaitu 0.557 , sedangkan untuk nilai sudut yang mendekati $0^{\circ}$ adalah Andi dan Ahmad yaitu cos 0.816 adalah 0.6154 .

\section{DAFTAR PUSTAKA}

[1] Rahma O, Warih M, dan Yanuar F (November, 2010). Content Base Recommender System Menggunakan Algoritma Apriori . Konferensi Nasional Sistem dan Informatika. Tersedia : https://docplayer.info/33681742-Content-based-recommender-system-menggunakan-algoritma-apriori.html

[2] Pinesti Natalia. (2010) Pengembangan Sistem Penunjang Keputusan Kelayakan Ekonomi dan Finansial Bagi Usaha Mikro Kecil Menengah. Jakarta.

[3] Susanto Hardo. (April, 2014) Perancangan Sistem Rekomendasi Pakaian Distro Dengan Menggunakan Item Collaborative Filtering (Studi Kasus : The Jungle Distro Medan) . Pelita Informatika Budi Darma, Volume : VI, Nomor: 3.

[4] Ramadhanuz A.D, Warih M, dan Angelina P.K . (November, 2010) Analisis Dan Implementasi Metode Item Based Clustering Hybrid Pada Recommender System . Konferensi Nasional Sistem dan Informatika 2010. Tersedia : https://openlibrary.telkomuniversity.ac.id/pustaka/94839/analisis-dan-implementasi-item-based-clustering-hybrid-method-recommender-system.html

[5] Rini S, Ekky P, Fakhria N.S, Ruth T, Angellica O.S. (Oktober, 2014) Sistem Rekomendasi Musik Menggunakan Latent Semantic Analysis. Prosiding Seminar Ilmiah Nasional Komputer dan Sistem Intelijen. Tersedia : https://ejournal.gunadarma.ac.id/index.php/kommit/article/download/1059/921

[6] Uyun Shofwatul. (Februari, 2011) Item Collaborative Filtering untuk Rekomendasi Pembelian Buku secara Online. JUSI Vol. 1, No. 1 . Tersedia : https://is.uad.ac.id/jusi/wp-content/uploads/07-JUSIVol-1-No-1-_Item-Collaborative-Filtering-untuk-Rekomendasi-Pembelian-Buku-secara-Online.pdf

[7] Wiranto Edi Winarko. (19 Juni, 2010) Konsep Multikriteria Collaborative Filtering Untuk Perbaikan Rekomendasi. Seminar Nasional Aplikasi Teknologi Informasi. Tersedia : https://journal.uii.ac.id/snati/article/download/1940/1715

[8] Rini S, Ekky P, Fakhria N.S, Ruth T, Angellica O.S. (2014) Sistem Rekomendasi Musik Menggunakan Latent Semantic Analysis. Depok.

[9] Susanto Hardo. (2014)Perancangan Sistem Rekomendasi Pakaian Distro Dengan Menggunakan Item Collaborative Filtering (Studi Kasus : The Jungle Distro Medan) . Medan.

[10] Pinesti Natalia. (2010) Pengembangan Sistem Penunjang Keputusan Kelayakan Ekonomi dan Finansial Bagi Usaha Mikro Kecil Menengah. Jakarta. 